\title{
Analysis of the constitution of the beer yeast genome by PCR, sequencing and subtelomeric sequence hybridization
}

1 Collection de Levures d'Intérêt

Biotechnologique, Laboratoire de Génétique Moléculaire et Cellulaire, CNRS URA1925, INRA

UMR216, Institut National Agronomique

Paris-Grignon, 78850

Thiverval Grignon, France

2 Department of Membrane Transport, Institute of Physiology, Czech Academy of Sciences, Videnska 1083, 14220 Prague 4, Czech Republic

\author{
Serge Casaregola, ${ }^{1}$ Huu-Vang Nguyen, ${ }^{1}$ Georgios Lapathitis, ${ }^{2}$ \\ Arnost Kotyk ${ }^{2}$ and Claude Gaillardin ${ }^{1}$
}

Author for correspondence: Serge Casaregola. Tel: +331308154 78. Fax: +33130815457. e-mail: serge@grignon.inra.fr

The lager brewing yeasts, Saccharomyces pastorianus (synonym Saccharomyces carlsbergensis), are allopolyploid, containing parts of two divergent genomes. Saccharomyces cerevisiae contributed to the formation of these hybrids, although the identity of the other species is still unclear. The presence of alleles specific to $S$. cerevisiae and $S$. pastorianus was tested for by PCR/RFLP in brewing yeasts of various origins and in members of the Saccharomyces sensu stricto complex. S. cerevisiae-type alleles of two genes, HIS4 and YCLO08c, were identified in another brewing yeast, S. pastorianus CBS 1503 (Saccharomyces monacensis), thought to be the source of the other contributor to the lager hybrid. This is consistent with the hybridization of $S$. cerevisiae subtelomeric sequences $X$ and $Y^{\prime}$ to the electrophoretic karyotype of this strain. $S$.

pastorianus CBS 1503 (S. monacensis) is therefore probably not an ancestor of S. pastorianus, but a related hybrid. Saccharomyces bayanus, also thought to be one of the contributors to the lager yeast hybrid, is a heterogeneous taxon containing at least two subgroups, one close to the type strain, CBS $3^{\circ}{ }^{\top}$, the other close to CBS 395 (Saccharomyces uvarum). The partial sequences of several genes (HIS4, MET10, URA3) were shown to be identical or very similar (over $99 \%$ ) in S. pastorianus CBS 1513 (S. carlsbergensis), S. bayanus CBS 380' and its close derivatives, showing that $S$. pastorianus and $S$. bayanus have a common ancestor. A distinction between two subgroups within $S$. bayanus was made on the basis of sequence analysis: the subgroup represented by $S$. bayanus CBS 395 (S. uvarum) has 6-8\% sequence divergence within the genes HIS4, MET1O and MET2 from S. bayanus CBS $380^{\top}$, indicating that the two $S$. bayanus subgroups diverged recently. The detection of specific alleles by PCR/RFLP and hybridization with S. cerevisiae subtelomeric sequences $X$ and $Y^{\prime}$ to electrophoretic karyotypes of brewing yeasts and related species confirmed our findings and revealed substantial heterogeneity in the genome constitution of Czech brewing yeasts used in production.

Keywords: brewing yeast, Saccharomyces pastorianus, Saccharomyces bayanus, hybrid genome, molecular taxonomy

\section{INTRODUCTION}

Brewing yeasts belong to two groups: top-fermenting yeasts, closely related to Saccharomyces cerevisiae and used for producing ale, and bottom-fermenting yeasts,

The EMBL accession numbers for the sequences determined in this study are AJ250961, AJ251006-AJ251012, AJ251575 and AJ251576. producing lager. The lager brewing yeasts form a heterogeneous species (Vaughan-Martini \& Martini, 1998), renamed Saccharomyces pastorianus (VaughanMartini \& Martini, 1987). S. pastorianus CBS 1513 (Saccharomyces carlsbergensis) was isolated by Hansen in the Carlsberg breweries in the 19th century; CBS 1513 and its close derivatives are the most studied lager brewing yeasts. These strains display features that have hampered genetic studies: they are non-maters, 
they sporulate poorly and they have very low spore viability. Several studies involving cytoduction combined with recombination and specific gene cloning and analysis have demonstrated that brewing yeasts are allopolyploid and that their genomes contain parts of two related but different genomes that have undergone numerous rearrangements (Nilsson-Tillgren et al., 1981; Casey, 1986a, b; reviewed by KiellandBrandt et al., 1995). The identities of the species that contributed to $S$. pastorianus are still unclear. Vaughan-Martini \& Kurtzman (1985) inferred from DNA-DNA reassociation tests with all members of the Saccharomyces sensu stricto group (S. cerevisiae, Saccharomyces bayanus, $S$. pastorianus and Saccharomyces paradoxus) that lager brewing yeasts are hybrids between $S$. cerevisiae and $S$. bayanus. Another hypothesis favours the formation of hybrids between $S$. cerevisiae and S. pastorianus CBS 1503 (Saccharomyces monacensis), a brewing yeast also isolated by Hansen in the Carlsberg breweries (Lodder \& Kregervan Rij, 1952) concomitantly with CBS 1513. The basis for this proposition is the presence of single alleles of particular genes such as HIS4, LEU2, MET2 and $A C B 1$ in CBS 1503 (S. monacensis), whereas $S$. pastorianus CBS 1513 (S. carlsbergensis) has two alleles for each of these genes, one identical to that in $S$. cerevisiae and one identical to that in CBS 1503 (S. monacensis) (Pedersen, 1983, 1986; Hansen \& Kielland-Brandt, 1994; Borsting et al., 1997). S. monacensis is represented by only one strain, CBS 1503. More recently, Andersen et al. (1999) inferred from PCR amplification that CBS 1503 contained $S$. cerevisiae material and therefore was an incomplete hybrid, but primer specificity and PCR product sequences were not documented.

Fujii et al. (1996) cloned the ATFl gene of $S$. pastorianus and showed a positive hybridization signal in $S$. bayanus DNA with this gene used as a probe, indicating the presence of a related gene in the latter species. Tamai et al. (1998) deduced from DNA hybridization studies that two chromosomes (one originating from S. cerevisiae and one from S. bayanus) co-existed in Japanese bottom-fermenting yeasts. Yamagishi \& Ogata (1999) showed further that chromosomes 8, 9, 12 and 14 of a derivative of $S$. bayanus CBS $380^{\mathrm{T}}$ were largely conserved in various bottom-fermenting yeasts including $S$. pastorianus CBS 1513 (S. carlsbergensis). Recent proteomic analysis with 2D gel electrophoresis confirmed the hybrid nature of the bottom-fermenting yeast genome and inferred that the second parent of these strains was a strain isolated from beer, NRRL Y-1551 ${ }^{\mathrm{T}}$, with an unclear taxonomic status but nevertheless assigned to S. pastorianus (Joubert et al., 2000). However, no DNA sequence data supported these observations obtained with either DNA hybridization or protein electrophoresis.

In parallel with the debate over the origin of the brewing yeast hybrid, the composition of the Saccharomyces sensu stricto complex of species is con- stantly being remodelled (Vaughan-Martini \& Martini, 1987; Barnett et al., 1990; Naumov, 1996; Vaughan-Martini \& Martini, 1998) as molecular methods increasingly challenge traditional classification (Kurtzman \& Robnett, 1998). Three new yeast species were recently added to this group (Naumov et al., 2000). The S. bayanus species was also reassessed recently and it was proposed that this taxon was heterogeneous on the basis of its rDNA sequence (Nguyen \& Gaillardin, 1997).

Few molecular methods are available that allow rapid characterization of the genome of the brewing yeasts (see Meaden, 1990) and, despite intensive work examining diversity within this species, very little variability has been found (Pedersen, 1983, 1985). The study of the brewing yeast genome can be laborious due to its complexity and the lack of information on its genetics. Nonetheless, analysis of genome composition is crucial to understanding the way that yeasts, domesticated by man over centuries, have evolved. We have undertaken the characterization of the genome of brewing yeasts related to $S$. pastorianus CBS 1513 (S. carlsbergensis) to improve the classification of the members of this species, to unravel the diversity within this species and to gain insights into the origin of these hybrids.

\section{METHODS}

Strains and plasmids. The yeast strains used in this study are listed in Table 1. The $\mathrm{Y}^{\prime}$ telomeric sequence on pJY5 was obtained from R. Degrée (Lavallée et al., 1994). The X telomeric sequence on $\mathrm{pXRIRV}$ was obtained from E. Louis (Dept of Biochemistry, Oxford University, UK).

Media. Cells were grown routinely in YPD ( $1 \%$ yeast extract, $1 \%$ peptone, $1 \%$ glucose) at $28^{\circ} \mathrm{C}$ with shaking. Standard procedures and genetic techniques were performed according to Sherman et al. (1986).

DNA techniques. Common DNA manipulations were performed as described by Sambrook et al. (1989). Restriction enzymes were purchased from Gibco-BRL and BioLabs. For cloning, the HIS4 fragment was purified from an agarose gel using a Geneclean kit (Bio 101). The protruding ends of the PCR-amplified fragment were filled in using a mixture of T4 DNA polymerase and Klenow polymerase (Stratagene), using the buffer provided and $0 \cdot 25 \mu \mathrm{M}$ dNTP. The fragments were then ligated into the SmaI site of pUC19 after dephosphorylation with alkaline phosphatase (Boehringer Mannheim). Blotting of DNA onto a GeneScreen nylon membrane (DuPont) was performed according to Zimmermann \& Fournier (1996). DNA-DNA hybridization was performed according to Church \& Gilbert (1984) with $\left[\alpha^{32} \mathrm{P}\right] \mathrm{dCTP}-\mathrm{labelled}$ DNA probes using the Megaprime labelling kit (Amersham) or in SSC buffer containing Denhardt's solution and $50 \%$ formamide at $42{ }^{\circ} \mathrm{C}$. Final washes were done at $65^{\circ} \mathrm{C}$ in $0 \cdot 1 \times \mathrm{SSC}, 0 \cdot 1 \% \mathrm{SDS}$.

Pulsed-field gel electrophoresis. Genomic DNA in agarose plugs was prepared according to Vézinhet et al. (1990) with slight modifications. Chromosomes were separated using a Bio-Rad CHEF DRII or MAPPER apparatus in $0.5 \times \mathrm{TBE}$ running buffer at $14{ }^{\circ} \mathrm{C}$ for $24 \mathrm{~h}$ with pulses from 40 to $120 \mathrm{~s}$ in $1 \%$ Seakem GTG agarose (FMC) gels at $6 \mathrm{~V} / \mathrm{cm}$. 
Table 1. List of strains used in this study

Culture collections are abbreviated as: CBS (Centraalbureau voor Schimmelcultures, Delft, The Netherlands), CCY (Czechoslovak Collection of Yeasts, Bratislava, Slovakia), DBVPG (Industrial yeast collection of the Dipartimentodi Biologia Vegetale, Perugia, Italy), MUCL (Mycothèque de 1'Université Catholique de Louvains, Belgium), NCYC (National Collection of Yeast Cultures, Norwich, UK) and NRRL (Agricultural Research Service Culture Collection, Peoria, USA). CBS numbers are given when available.

\begin{tabular}{|c|c|}
\hline Strain & Other strain designation(s) \\
\hline \multicolumn{2}{|l|}{ Strains from collections } \\
\hline S. bayanus CLIB $181^{\mathrm{T}}$ & NRRL Y-1262 $($ CBS 380 $)$ \\
\hline S. bayanus CLIB 534 & CBS 378 \\
\hline S. bayanus CLIB 255 (syn. S. heterogenicus) & DBVPG 6294 (CBS 425) \\
\hline S. bayanus CLIB 254 (syn. S. intermedius) & DBVPG 6260 (CBS 1505) \\
\hline S. bayanus CLIB 251 (syn. S. uvarum) & DBVPG 6179 (CBS 395) \\
\hline S. cerevisiae CLIB $227^{\mathrm{NT}}$ & MUCL $31497^{\mathrm{NT}}$ (CBS $\left.1171^{\mathrm{NT}}\right)$ \\
\hline S. cerevisiae CLIB 112 & YNN295 \\
\hline S. pastorianus CLIB 176 (syn. S. carlsbergensis) & NRRL Y-12693 (CBS 1513) \\
\hline S. pastorianus CLIB 180 (syn. S. monacensis) & NRRL Y-1525 (CBS 1508) \\
\hline S. pastorianus CLIB 271 & SpK17 (CCY 21-6-1) \\
\hline S. pastorianus CLIB 276 & MUCL 28282 \\
\hline S. pastorianus CLIB 277 & MUCL 28283 \\
\hline S. pastorianus CLIB 278 & MUCL 28284 \\
\hline S. pastorianus CLIB 279 & MUCL 28285 \\
\hline S. pastorianus CLIB $537^{\mathrm{T}}$ & CBS $1538^{\mathrm{T}}$ \\
\hline S. pastorianus CLIB $281^{\mathrm{T}}$ & NRRL Y-1551 \\
\hline \multicolumn{2}{|l|}{ Czech brewing strains isolated as part of this work } \\
\hline Top 75 & CLIB 220 \\
\hline Top 76 & CLIB 221 \\
\hline Branik bottom 1 & CLIB 223 \\
\hline Smichov bottom 2 & CLIB 224 \\
\hline Trebon bottom 96 & CLIB 225 \\
\hline Budvar H 2 & CLIB 259 \\
\hline Holosevice B 3 & CLIB 260, NCYC 680 \\
\hline Holosevice C 4 & CLIB 261, NCYC 681 \\
\hline Pilsen D & CLIB 262 \\
\hline Pilsen $\mathrm{H} 7$ & CLIB 263 \\
\hline Pilsen W & CLIB 264 \\
\hline Smichow A9 & CLIB 265 \\
\hline Smichow H10 & CLIB 266 \\
\hline Weiden Stephen 95 & CLIB 267 \\
\hline
\end{tabular}

PCR amplification. The primers used for PCR amplification are listed in Table 2. The OLIGO primer analysis software (National Biosciences Inc.) was used for the design of the primers with the MIPS yeast genome database and the EMBL database. PCR amplifications were performed with $50 \mathrm{ng}$ genomic DNA, prepared according to Hoffman \& Winston (1987), using a Crocodile III or a Perkin-Elmer 9600 thermocycler. Amplification conditions were: $4 \mathrm{~min}$ at $94{ }^{\circ} \mathrm{C}, 25$ or 30 cycles of $30 \mathrm{~s}$ at $94{ }^{\circ} \mathrm{C}, 30 \mathrm{~s}$ at the $T_{\mathrm{m}}$ of the primers, and $1 \mathrm{~min}$ per $\mathrm{kb}$ to be amplified at $72^{\circ} \mathrm{C}$, followed by 7 min at $72{ }^{\circ} \mathrm{C}$. Appligene $\operatorname{Taq}$ polymerase ( $2.5 \mathrm{U}$; Oncor) was used with the buffer supplied. The PCR products were run on a $0.8 \%$ agarose gel $(\mathrm{ICN})$ in $1 \times$ TAE buffer. For the amplification of the PCR products to be sequenced, $1 \mathrm{U} P f u$ polymerase (Stratagene) was added to each reaction.

Purification of PCR products. PCR products were purified for sequencing by using GELase (Epicentre) essentially according to the manufacturer's recommendations. DNA separated on a $1 \%$ low-gelling Seaplaque agarose gel (FMC) was cut out and incubated in the buffer supplied (40 mM BisTris/ $\mathrm{HCl} \mathrm{pH}$ 6, $40 \mathrm{mM} \mathrm{NaCl}, 1 \mathrm{mM}$ EDTA) for $1 \mathrm{~h}$ at room temperature. The agarose was melted at $70^{\circ} \mathrm{C}$ for $20 \mathrm{~min}$, incubated for $10 \mathrm{~min}$ at $45^{\circ} \mathrm{C}$ and GELase $(1 \mathrm{U}$ per $600 \mathrm{mg}$ agarose) was added. After a $1 \mathrm{~h}$ incubation at $45^{\circ} \mathrm{C}$, DNA was precipitated with ethanol, resuspended in TE and used as the template for sequencing. Escherichia coli tRNA was sometimes added as a carrier $\left(10 \mu \mathrm{g} \mathrm{ml}^{-1}\right.$ final concentration $)$ but did not interfere with the sequencing reactions.

Sequencing. Sequencing was performed essentially as described by Maftahi et al. (1995). Sequences were compiled and analysed using the Staden package (Dear \& Staden, 1991) and FASTA (Pearson \& Lipman, 1988) in the GCG 
Table 2. List of primers

\begin{tabular}{|c|c|c|}
\hline Primer & Sequence $\left(5^{\prime}-3^{\prime}\right)$ & Origin \\
\hline HIS4-U & ACT CTA ATA GTG ACT CCG & $\begin{array}{l}\text { Consensus sequence, } S \text {. pastorianus and } S \text {. cerevisiae HIS4 } \\
\text { gene }\end{array}$ \\
\hline HIS4-L & AAC TTG GGA GTC AAT ACC & $\begin{array}{l}\text { Consensus sequence, } S \text {. pastorianus and } S \text {. cerevisiae HIS4 } \\
\text { gene }\end{array}$ \\
\hline YCL008c-U & TTC GTT GGA TGT GCC ATC G & $\begin{array}{l}\text { Consensus sequence, S. pastorianus and S. cerevisiae YCLO08c } \\
\text { gene }\end{array}$ \\
\hline YCL008c-L & GGA GCC ACC AAG GGA TGG & $\begin{array}{l}\text { Consensus sequence, } S \text {. pastorianus and } S \text {. cerevisiae YCLO08c } \\
\text { gene }\end{array}$ \\
\hline URA3-U & GCA CAG AAC AAA AAC CT & Sequence specific to $S$. cerevisiae $U R A 3$ gene \\
\hline URA3-L & TCA TTA CGA CCG AGA TT & Sequence specific to $S$. cerevisiae $U R A 3$ gene \\
\hline URA3pa-U & TTG ACT GAC TTT TCC AT & Sequence specific to $S$. pastorianus $U R A 3$ gene \\
\hline URA3pa-L & СCT CTT CCC ACG ATA AT & Sequence specific to $S$. pastorianus $U R A 3$ gene \\
\hline MET2-U & CGA AAA CGC TCC AAG AGC TGG & $\begin{array}{l}\text { Consensus sequence, S. pastorianus and S. cerevisiae } \\
\text { (Hansen \& Kielland-Brandt, 1994) }\end{array}$ \\
\hline MET2-L & GAC CAC GAT ATG CAC CAG GCA G & $\begin{array}{l}\text { Consensus sequence, S. pastorianus and S. cerevisiae } \\
\text { (Hansen \& Kielland-Brandt, 1994) }\end{array}$ \\
\hline MET10-U & ATC ACT TAT GGG TCT TT & Sequence specific to $S$. cerevisiae $M E T 10$ gene \\
\hline MET10-L & TTC TTC CTT TAT TAT CC & Sequence specific to $S$. cerevisiae MET10 gene \\
\hline MET10pa-U & TAT GGG TCT TTG GAA TC & Sequence specific to $S$. pastorianus MET10 gene \\
\hline MET10pa-L & TCA GGT CTC AGT TTG TT & Sequence specific to $S$. pastorianus MET10 gene \\
\hline NL1 & GCA TAT CAA TAA GCG GAG GAA AAG & $\begin{array}{l}\text { Universal primer for amplification of the D1/D2 region } \\
\text { of rDNA (O'Donnell, 1993) }\end{array}$ \\
\hline NL4 & GGT CCG TGT TTC AAG ACG G & $\begin{array}{l}\text { Universal primer for amplification of the D1/D2 region } \\
\text { of rDNA (O'Donnell, 1993) }\end{array}$ \\
\hline
\end{tabular}

environment (Genetics Computer Group, Madison, WI, USA).

\section{RESULTS AND DISCUSSION}

\section{Detection of specific alleles in brewing strains}

We tested for the presence of alleles specific to $S$. cerevisiae and $S$. pastorianus in brewing yeasts of diverse origins and in the Saccharomyces sensu stricto species (list of strains in Table 1) using the available sequences of $S$. pastorianus CBS 1513 (S. carlsbergensis). In order to discriminate between brewing yeasts and to identify the contributing species, we assessed the distribution of markers of other species possibly involved in the creation of the brewing yeast hybrids. Initially, $S$. bayanus CBS $380^{\mathrm{T}}$ and $S$. pastorianus CBS 1503 (S. monacensis) were tested, as several authors have suggested that these species, together with $S$. cerevisiae, gave rise to such hybrids. Regions of the genome were amplified by PCR (i) with primers designed using regions that are completely identical in S. pastorianus and S. cerevisiae, and PCR products were then analysed for RFLP, and (ii) with primers designed from divergent sequences of homologous genes from the two species, and the sizes of the PCR products were monitored.

Primers common to CBS 1513 and S. cerevisiae were designed from sequences within the HIS4 (Porter et al., 1996) and YCLO08c genes (EMBL accession no.
Z86109). We also used the primers designed by Hansen \& Kielland-Brandt (1994) to amplify the MET2 gene and the primers designed by Nguyen \& Gaillardin (1997) to amplify the rDNA non-transcribed spacer 2 (NTS2). For MET10 and URA3, we designed pairs of primers specific for each of the species studied (Hansen et al., 1994; Gjermansen, 1991). Pairs of primers derived from other gene sequences (ILV2, YCLO10c) failed to give PCR products for at least one species. This could be due to sequencing errors or to strain sequence specificity. The primers are described in Table 2. Overall, we were able to test specific markers present on five chromosomes of $S$. cerevisiae: chromosomes III, V, VI, XIV and XII. Chromosome XII carries the rDNA repeats.

Fig. 1 shows examples of PCR amplification of part of the URA3 gene (Fig. 1a) and RFLP restriction patterns of PCR products of part of the HIS4 gene (Fig. 1b) for S. cerevisiae, S. pastorianus CBS 1513, S. pastorianus CBS 1503 and S. bayanus CBS $380^{\mathrm{T}}$. For $U R A 3$, a $0.9 \mathrm{~kb}$ PCR product was generated from $S$. cerevisiae and S. pastorianus CBS 1513 with primers specific for $S$. cerevisiae, whereas a $0.6 \mathrm{~kb}$ PCR product was obtained from $S$. pastorianus CBS 1513, $S$. pastorianus CBS 1503 and $S$. bayanus CBS $380^{\mathrm{T}}$ with primers deduced from the $S$. pastorianus sequence (Fig. 1a). Thus, there is one allele of the $U R A 3$ gene in all strains except $S$. pastorianus CBS 1513, in which there are two alleles, as expected (Gjermansen, 1991). 

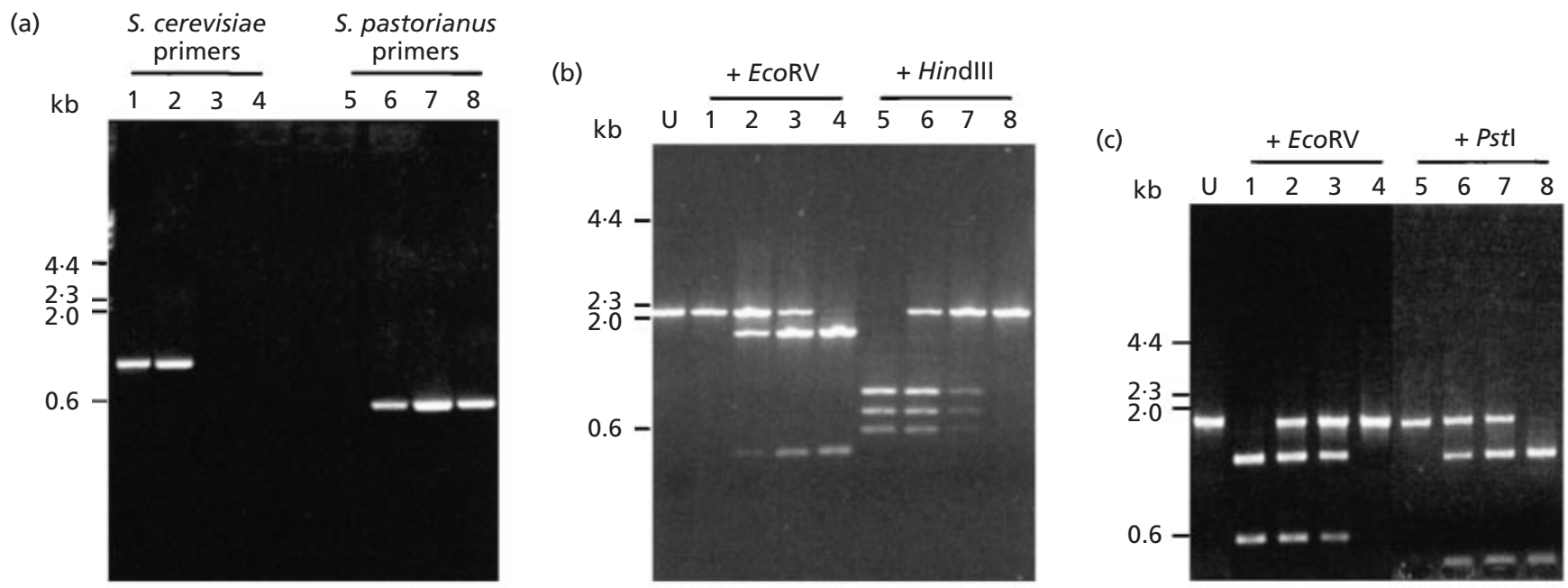

Fig. 1. $P C R$ amplification of specific alleles of HIS4, URA3 and YCLOO8C with genomic DNA from type strains as templates. Lanes: 1 and 5, S. cerevisiae CBS $1171^{\mathrm{NT}} ; 2$ and 6, S. pastorianus CBS 1513 (S. carlsbergensis), 3 and 7, S. pastorianus CBS 1503 (S. monacensis); 4 and 8, S. bayanus CBS 380'. (a) Lanes: 1-4, PCR amplification with primers URA3-U and URA3-L, specific for the $S$. cerevisiae URA3 gene; 5-8, PCR amplification with primers URA3pa-U and URA3pa-L, specific for the $S$. pastorianus CBS 1513 URA3 gene. (b) Lanes: PCR amplification with primers HIS4-U and HIS4-L followed by digestion of the PCR products with ECORV (lanes 1-4) or HindIII (lanes 5-8). Lane U contains the undigested PCR product, included as a control. (c) PCR amplification with primers YCL008C-U and YCL008c-L followed by digestion of the PCR products with EcoRV (lanes 1-4) or Pstl (lanes 5-8). Lane U contains the undigested PCR product, included as a control. Positions of molecular mass markers are indicated on the left.

Table 3. Distribution of specific alleles in various Saccharomyces species

$\mathrm{Sc}, \mathrm{Sp}$ and $\mathrm{Su}$ correspond to sequences identical to those in $S$. cerevisiae, S. pastorianus (as S. bayanus) and $S$. uvarum, respectively. The reference sequences are that of $S$. cerevisiae (from servers SGD and MIPS) and the published sequence of $S$. pastorianus CBS 1513 (S. carlsbergensis) as described in the text and present in NCBI and EMBL databases except for the partial S. pastorianus CBS 1513 (S. carlsbergensis) URA3 gene, which was resequenced in this work (accession no. AJ251006). Accession numbers of sequences determined during this work are given in parentheses. The presence of the $\mathrm{X}$ and $\mathrm{Y}^{\prime}$ sequences is indicated as: - , absent; + , present; +++ , present in large numbers. n.a., Not available.

\begin{tabular}{|c|c|c|c|c|c|c|c|c|}
\hline Marker & $\begin{array}{l}\text { S. cerevisiae } \\
\text { chromosome }\end{array}$ & Comparison & Allele size (kb) & 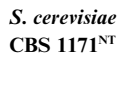 & $\begin{array}{c}\text { S. pastorianus } \\
\text { CBS } 1513 \\
\text { (S. carlsbergensis) }\end{array}$ & $\begin{array}{c}\text { S. pastorianus } \\
\text { CBS } 1503 \\
\text { (S. monacensis) }\end{array}$ & $\begin{array}{l}\text { S. bayanus } \\
{\text { CBS } 380^{\mathrm{T}}}^{\text {Th }}\end{array}$ & $\begin{array}{c}\text { S. bayanus } \\
\text { CBS } 395 \\
\text { (S. uvarum) }\end{array}$ \\
\hline ScHIS4 & III & Restriction profile and sequence & $2 \cdot 1$ & Sc & $\mathrm{Sc}$ & Sc (AJ250961) & & \\
\hline SpHIS4 & & & $2 \cdot 1$ & & $\mathrm{Sp}$ & $\mathrm{Sp}$ & Sp (AJ251575) & \\
\hline SuHIS4 & & & $2 \cdot 1$ & & & & & $\mathrm{Su}(\mathrm{AJ} 251576)$ \\
\hline ScYCLO08c & III & Restriction profile and sequence & $1 \cdot 6$ & Sc & $\mathrm{Sc}$ & $\mathrm{Sc}$ & & \\
\hline $\operatorname{SpYLC008c}$ & & & $1 \cdot 6$ & & $\mathrm{Sp}$ & $\mathrm{Sp}$ & Sp (sequence n.a.) & \\
\hline SuYLC008c & & & $1 \cdot 6$ & & & & & $\mathrm{Su}(\mathrm{AJ} 251012)$ \\
\hline ScMETIO & VI & Amplification and sequence & $1 \cdot 7$ & Sc & & & & \\
\hline SpMET10 & & & $1 \cdot 1$ & & $\mathrm{Sp}$ & $\mathrm{Sp}$ & $\mathrm{Sp}(\mathrm{AJ} 251008)$ & \\
\hline SUMET10 & & & $1 \cdot 7$ & & & & & $\mathrm{Su}(\mathrm{AJ} 251009)$ \\
\hline ScURA3 & $\mathrm{V}$ & Amplification and sequence & $0 \cdot 9$ & Sc & $\mathrm{Sc}$ & & & \\
\hline $\operatorname{SpURA3}$ & & & $0 \cdot 5$ & & $\mathrm{Sp}$ & $\mathrm{Sp}(\mathrm{AJ} 251006)$ & $\mathrm{Sp}(\mathrm{AJ} 251007)$ & \\
\hline ScMET2 & XIV & Restriction profile and sequence & $0 \cdot 6$ & $\mathrm{Sc}$ & $\mathrm{Sc}$ & & & \\
\hline SpMET2 & & & $0 \cdot 6$ & & $\mathrm{Sp}$ & $\mathrm{Sp}$ & & \\
\hline SuMET2 & & & $0 \cdot 6$ & & & & $\mathrm{Su}$ & $\mathrm{Su}$ \\
\hline rDNA $26 \mathrm{~S}$ D1/D2 & XII & Sequence & $0 \cdot 6$ & Sc & & & & \\
\hline rDNA $26 \mathrm{~S}$ D1/D2 & & & $0 \cdot 6$ & & $\mathrm{Sp}$ & $\mathrm{Sp}^{*}$ & $\mathrm{Sp}$ & $\mathrm{Sp}$ \\
\hline rDNA NTS2 type I & XII & Restriction profile $\dagger$ & $1 \cdot 3$ & $\mathrm{Sc}$ & & & & \\
\hline rDNA NTS2 type II & & & $1 \cdot 3$ & & & & $\mathrm{Su}$ & $\mathrm{Su}$ \\
\hline rDNA NTS2 type III & & & $1 \cdot 3$ & & $\mathrm{Sp}$ & $\mathrm{Sp}$ & $\mathrm{Sp}$ & \\
\hline $\mathrm{X}$ sequence & All & Hybridization & - & +++ & +++ & +++ & + & - \\
\hline $\mathrm{Y}^{\prime}$ sequence & Most & Hybridization & - & +++ & +++ & +++ & + & - \\
\hline
\end{tabular}

* The sequences of CBS 1513 and CBS $380^{\mathrm{T}}$ (this work, not shown) and the published sequence of S. pastorianus NRRL Y-1551 (Kurtzman \& Robnett, 1998) are identical. The CBS 1503 sequence displays a 1 bp mismatch relative to these sequences (this work, not shown).

$\dagger$ Data taken from Nguyen \& Gaillardin (1997). 
For HIS4, an identical $2.1 \mathrm{~kb}$ PCR fragment was obtained in all strains (Fig. 1b, lane U). In order to distinguish between the HIS4 alleles in S. pastorianus, the $2 \cdot 1 \mathrm{~kb}$ PCR product was digested with EcoRV. Two fragments, of around 1.7 and $0.5 \mathrm{~kb}$, were expected from the $S$. pastorianus HIS4 gene sequence, whilst the $2 \cdot 1 \mathrm{~kb}$ PCR product amplified from the $S$. cerevisiae allele was expected to remain intact, since no EcoRV site exists in the published sequence. HindIII digestion was expected to cleave the HIS4 PCR product amplified from the $S$. cerevisiae allele into three fragments, of about $0.8,0.7$ and $0.6 \mathrm{~kb}$. The expected patterns were obtained for $S$. cerevisiae (Fig. $1 \mathrm{~b}$, lanes 1 and 5). In $S$. bayanus CBS $380^{\mathrm{T}}$, two fragments, of around 1.7 and $0.5 \mathrm{~kb}$, were obtained after EcoRV digestion (lane 4), but no HindIII site was present in the $2.1 \mathrm{~kb}$ fragment (lane 8 ). The more complex patterns obtained with $S$. pastorianus CBS 1513 (lanes 2 and 6) and S. pastorianus CBS 1503 (lanes 3 and 7) can be explained as a combination of the restriction patterns of an $S$. cerevisiae-type allele and an $S$. bayanus-type allele.

These results indicate that, as in $S$. pastorianus CBS 1513 , both the $S$. cerevisiae-type and $S$. bayanus-type alleles are present in $S$. pastorianus CBS 1503 ( $S$. monacensis). This prompted us to test other markers and, in particular, the $Y C L 008 \mathrm{c}$ gene located at $\mathrm{kb}$ 105-107 of chromosome III, in a $10 \mathrm{~kb}$ region sequenced by T. Andersen and T. Nilsson-Tillgren (accession no. Z86109). We obtained a result similar to that obtained with the HIS4 alleles. A $1.6 \mathrm{~kb}$ fragment was generated from all strains by amplification with one pair of primers (Fig. 1c, lane U). In S. cerevisiae, the $E c o \mathrm{RV}$ digestion yielded two fragments, of $1 \cdot 1$ and $0.5 \mathrm{~kb}$, whereas Pst I digestion left the $1.6 \mathrm{~kb}$ DNA fragment intact, since it does not contain a PstI site (Fig. 1c, lanes 1 and 5). In S. bayanus, the expected $S$. pastorianus EcoRV restriction pattern was obtained: two fragments, of 1.2 and $0.3 \mathrm{~kb}$, plus another fragment of $140 \mathrm{~kb}$, too small to be visible under the gel migration conditions used in Fig. 1. As with HIS4, S. pastorianus CBS 1513 and CBS 1503 displayed restriction patterns corresponding to a combination of the $S$. cerevisiae and $S$. bayanus patterns.

The results concerning the distribution of alleles in the four strains are summarized in Table 3. We obtained the same results as Hansen \& Kielland-Brandt (1994) with MET2. PCR products of $0.6 \mathrm{~kb}$, distinguishable by their restriction patterns and specific to $S$. cerevisiae and $S$. pastorianus CBS 1503, were found in $S$. pastorianus CBS 1513, whereas $S$. bayanus CBS $380^{\mathrm{T}}$ and S. bayanus CBS 395 (Saccharomyces uvarum) contained a third, different $M E T 2$ allele (Table 3). For MET10, a PCR product of about $1.7 \mathrm{~kb}$ was obtained from $S$. cerevisiae with $S$. cerevisiae-specific primers, whereas a PCR product of about $1 \cdot 1 \mathrm{~kb}$ was obtained with the $S$. pastorianus-specific primers. The sizes of the PCR products were as expected from the published sequence. Interestingly, a single $1 \cdot 1 \mathrm{~kb}$ PCR product was obtained from $S$. pastorianus CBS 1513 with each of the two pairs of primers used, suggesting that this strain harbours only the $S$. pastorianus allele.

\section{Sequence analysis of specific alleles in Saccharomyces species}

The presence of two different HIS4 alleles in $S$. pastorianus CBS 1503 (S. monacensis) suggested that this strain is a hybrid. We decided to confirm that sequences originating from $S$. cerevisiae were present in $S$. pastorianus CBS 1503 . The mixture of the two $2 \cdot 1 \mathrm{~kb}$ PCR fragments obtained from $S$. pastorianus CBS 1503 using the HIS4 primers (see Fig. 1b, lane U) was digested with EcoRV. This restriction enzyme cleaves the $S$. pastorianus allele but does not cleave the $S$. cerevisiae allele. The resulting fragments were separated on an agarose gel (Fig. 1b, lane 3). The remaining $2 \cdot 1 \mathrm{~kb}$ PCR fragment was then purified from the gel, end-repaired and inserted into pBluescript. The sequence of $392 \mathrm{bp}$ of one of the PCR products was determined (accession no. AJ250961) and compared to the published $S$. cerevisiae sequence. There were only two mismatches in the $S$. pastorianus CBS 1503 sequence: a $C$ replaced a $G$ in the promoter region at position -207 and a $G$ replaced a $T$ in the coding region at position +32 with respect to the start ATG. The replacement at +32 modifies the third base of the codon to give a conserved substitution: Asp in $S$. cerevisiae and Glu in CBS 1503 . This $99.5 \%$ identity shows clearly that the sequenced $S$. pastorianus CBS 1503 (S. monacensis) fragment originated from $S$. cerevisiae, since the sequence identity of the same region between $S$. cerevisiae and $S$. pastorianus was only $81.5 \%$ (data not shown). Using PCR/RFLP, we showed that the $S$. cerevisiae YCL008c allele was present in S. monacensis. The HIS4 and YCLO08c genes are both on the left arm of $S$. cerevisiae chromosome III, at $\mathrm{kb} 65-68$ and 105-107, respectively, suggesting that a stretch of $S$. cerevisiae chromosome spanning $40 \mathrm{~kb}$ is present in $S$. monacensis. Yamagishi \& Ogata (1999) hinted that $S$. cerevisiae material was present in $S$. pastorianus CBS 1503 (S. monacensis). Andersen et al. (1999) also suggested that this strain was a hybrid. We show here by sequence analysis and PCR/RFLP that this clearly is the case.

We analysed the sequence of the HIS4 gene in other related yeasts to gain insight into the origin of other contributors to the bottom-brewing yeasts, using the two primers defined for S. cerevisiae and S. pastorianus (Table 2). The species $S$. bayanus was shown to be heterogeneous (Nguyen \& Gaillardin, 1997). Two subgroups were found in this taxon: one subgroup represented by S. bayanus CBS 395 (syn. S. uvarum) and the other represented by the type strain, S. bayanus CBS $380^{\mathrm{T}}$. Genomic DNA from two cultures of the $S$. pastorianus type strain, NRRL Y-1551 ${ }^{\mathrm{T}}$, obtained from the ARS (Peoria, IL, USA), and CBS $1538^{\mathrm{T}}$, obtained from the CBS (Delft, The Netherlands), and from diverse S. bayanus strains, CBS $380^{\mathrm{T}}$, CBS 378 , CBS 1505 (syn. Saccharomyces intermedius), CBS 425 (syn. Saccharomyces heterogenicus) and CBS 395 (S. 
Table 4. Percentage DNA sequence identity between alleles in various Saccharomyces species

The reference sequences are described in the legend to Table 3 . The accession numbers of each sequence determined in this study are indicated in Table 3 and in the text. NA, Not available.

\begin{tabular}{|c|c|c|c|}
\hline Allele & S. pastorianus & S. bayanus CBS $380^{\mathrm{T}}$ & $\begin{array}{c}\text { S. bayanus CBS } 395 \\
\text { (S. uvarum) }\end{array}$ \\
\hline \multicolumn{4}{|l|}{ HIS4 } \\
\hline S. cerevisiae & $79 \cdot 2$ & $79 \cdot 2$ & $78 \cdot 4$ \\
\hline S. pastorianus & 100 & 100 & $93 \cdot 7$ \\
\hline S. bayanus CBS $380^{\mathrm{T}}$ & - & 100 & $93 \cdot 7$ \\
\hline \multicolumn{4}{|l|}{ MET10 } \\
\hline S. cerevisiae & $77 \cdot 7$ & $77 \cdot 7$ & $79 \cdot 2$ \\
\hline S. pastorianus & 100 & 100 & 92 \\
\hline S. bayanus CBS $380^{\mathrm{T}}$ & - & 100 & 92 \\
\hline \multicolumn{4}{|l|}{ YCL008c } \\
\hline S. cerevisiae & $77 \cdot 2$ & NA & $76 \cdot 2$ \\
\hline S. pastorianus & 100 & NA & $93 \cdot 4$ \\
\hline S. bayanus CBS $380^{\mathrm{T}}$ & - & NA & NA \\
\hline \multicolumn{4}{|l|}{$U R A 3$} \\
\hline S. cerevisiae & $82 \cdot 2$ & $82 \cdot 2$ & NA \\
\hline S. pastorianus & 100 & 100 & NA \\
\hline S. bayanus CBS $380^{\mathrm{T}}$ & - & 100 & NA \\
\hline \multicolumn{4}{|l|}{ MET2 } \\
\hline S. cerevisiae & 82 & $81 \cdot 9$ & $81 \cdot 9$ \\
\hline S. pastorianus & 100 & $92 \cdot 8$ & $92 \cdot 8$ \\
\hline S. bayanus CBS $380^{\mathrm{T}}$ & - & 100 & 100 \\
\hline
\end{tabular}

uvarum), was used as PCR templates with the HIS4 primers. A PCR amplification product of a size similar to that obtained from $S$. cerevisiae, $S$. pastorianus and $S$. bayanus, i.e. $2 \cdot 1 \mathrm{~kb}$, was obtained for all of these strains. Some 375 bp of the $5^{\prime}$ end of each of the PCR products was sequenced. The first strand was sequenced and a second primer, deduced from the $3^{\prime}$ end sequence, was used to sequence the second strand. Except for CBS 395 (S. uvarum), which was found to be clearly divergent from $S$. pastorianus, and CBS 425 , which had four bases deleted compared with $S$. pastorianus, the sequences of all the strains tested were $100 \%$ identical to the $S$. pastorianus sequence (see Table 3; CBS $380^{\mathrm{T}}$ accession no. AJ251575 and data not shown). These results show that a group comprising $S$. pastorianus CBS 1513 (S. carlsbergensis), $S$. pastorianus CBS 1503 (S. monacensis), S. bayanus CBS $380^{\mathrm{T}}$ and several $S$. bayanus strains is defined by an identical HIS4 sequence. This indicates that the lager brewing yeasts, $S$. pastorianus, tested here share a sequence that is conserved in several $S$. bayanus strains and that they have a common ancestor.

Surprisingly, the sequence of S. bayanus CBS 395 (accession no. AJ251576) was $93.7 \%$ identical to that of $S$. pastorianus and $79 \cdot 2 \%$ identical to that of $S$. cerevisiae. This clearly distinguished the $S$. bayanus subgroup represented by CBS 395 (S. uvarum) from the other $S$. bayanus strains. Thus, four groups of strains, defined by $S$. cerevisiae, $S$. pastorianus, $S$. bayanus and S. bayanus CBS 395 (S. uvarum), can be differentiated on the basis of the HIS4 sequence.

We amplified and sequenced further alleles from these strains (summarized in Table 4). Partial sequences of the MET10 alleles were obtained from PCR products amplified from $S$. bayanus CBS $380^{\mathrm{T}}$ (accession no. AJ251008) and S. bayanus CBS 395 (accession no. AJ251009). The sequence from $S$. bayanus CBS $380^{\mathrm{T}}$ was identical to the published $S$. pastorianus sequence, whereas the CBS 395 sequence was $92 \%$ identical to that of S. pastorianus and $79 \cdot 2 \%$ identical to that of $S$. cerevisiae over a $673 \mathrm{bp}$ stretch, consistent with the result obtained for the HIS4 gene. A total of $429 \mathrm{bp}$ of the $5^{\prime}$ end of the $U R A 3$ gene PCR product amplified from $S$. bayanus CBS $380^{\mathrm{T}}$ (accession no. AJ251007) was $100 \%$ identical to the $S$. pastorianus sequence. These sequences could not be compared to that of the CBS 395 URA3 allele because no amplification product was obtained, suggesting that the CBS 395 sequence is divergent from that of $S$. bayanus CBS $380^{\mathrm{T}}$. For YCL008c, the allele from CBS 395 (S. uvarum) (accession no. AJ251012) displayed $93.4 \%$ identity to that of $S$. pastorianus and $76 \cdot 2 \%$ identity to that of $S$. cerevisiae over a $440 \mathrm{bp}$ stretch. We were unable to sequence the $S$. bayanus CBS $380^{\mathrm{T}}$ allele directly. However, we were able to amplify and sequence the same fragment from another S. bayanus strain, CBS 1505 ( $S$. intermedius), the sequence of which was identical to that of $S$. pastorianus. Thus, the $S$. 
Table 5. Presence of alleles specific to $S$. cerevisiae and S. pastorianus in various $S$. pastorianus strains

The presence of an allele of each of the markers is indicated by Sc, Sp and Su for S. cerevisiae-type, S. pastorianus-type and $S$. uvarum-type with respect to the origin of the alleles, as defined in the text and Tables 3 and 4. ND, Not determined.

\begin{tabular}{|lccccccc|}
\hline Strain & HIS4 & YCLO08c & MET2 & URA3 & MET10 & \multirow{2}{*}{ D1/D2 (rDNA) } & NTS2 (rDNA) \\
\hline MUCL 28282 & $\mathrm{Sp}$ & $\mathrm{Sp}$ & $\mathrm{Sc} / \mathrm{Sp}$ & $\mathrm{Sc} / \mathrm{Sp}$ & $\mathrm{Sp}$ & $\mathrm{ND}$ & $\mathrm{Sp}$ \\
MUCL 28283 & $\mathrm{Sc} / \mathrm{Sp}$ & $\mathrm{Sc} / \mathrm{Sp}$ & $\mathrm{Sc} / \mathrm{Sp}$ & $\mathrm{Sp}$ & $\mathrm{Sp}$ & $\mathrm{ND}$ & $\mathrm{Sp}$ \\
MUCL 28284 & $\mathrm{Sp}$ & $\mathrm{Sp}$ & $\mathrm{Sc} / \mathrm{Sp}$ & $\mathrm{Sc} / \mathrm{Sp}$ & $\mathrm{Sc} / \mathrm{Sp}$ & $\mathrm{ND}$ & $\mathrm{Sc}$ \\
MUCL 28285 & $\mathrm{Sc} / \mathrm{Sp}$ & $\mathrm{Sc} / \mathrm{Sp}$ & $\mathrm{Sc} / \mathrm{Sp}$ & $\mathrm{Sc} / \mathrm{Sp}$ & $\mathrm{Sc} / \mathrm{Sp}$ & $\mathrm{Sc}$ & $\mathrm{Sc}$ \\
14 Czech strains & $\mathrm{Sc} / \mathrm{Sp}$ & $\mathrm{Sc} / \mathrm{Sp}$ & $\mathrm{Sc} / \mathrm{Sp}$ & $\mathrm{Sc} / \mathrm{Sp}$ & $\mathrm{Sc} / \mathrm{Sp}$ & $\mathrm{ND}$ & $\mathrm{Sc}$ \\
NRRL Y-1551 & $\mathrm{Sp}$ & $\mathrm{Sp}$ & $\mathrm{Su}$ & $\mathrm{ND}$ & $\mathrm{ND}$ & $\mathrm{Sp}$ & $\mathrm{Sp}$ \\
CBS 1538 & $\mathrm{Sp}$ & $\mathrm{Sp}$ & $\mathrm{Sc} / \mathrm{Sp}$ & $\mathrm{ND}$ & $\mathrm{ND}$ & $\mathrm{ND}$ & $\mathrm{Sp}$ \\
\hline
\end{tabular}

pastorianus-specific and S. bayanus-specific sequences tested are identical, whereas the sequences from $S$. bayanus CBS 395 (S. uvarum) are clearly different, systematically displaying 6-8\% divergence from the sequences of the group composed of $S$. bayanus and $S$. pastorianus and $21-24 \%$ divergence from the $S$. cerevisiae group. This indicates that $S$. bayanus and $S$. bayanus CBS 395 ( $S$. uvarum) diverged more recently.

These results nevertheless contradict both the sequence identity of the MET2 genes in S. bayanus CBS $380^{\mathrm{T}}$ and $S$. bayanus CBS 395 (S. uvarum) and their divergence from the $S$. pastorianus counterpart as demonstrated by Hansen \& Kielland-Brandt (1994). We looked for $S$. bayanus strains with $S$. pastorianus characteristics by amplifying and sequencing the $M E T 2$ gene. We found that $S$. bayanus CBS 1505 ( $S$. intermedius) and S. bayanus CBS 425 (S. heterogenicus) carry an $S$. pastorianus-type MET2 gene, with sequences identical to that of $S$. pastorianus over 447 and $430 \mathrm{bp}$, respectively (data not shown). Strains such as CBS 1505 and CBS 425 are therefore good candidates for having been involved in the formation of the modern lager hybrids. Transfer of DNA material must have occurred between S. bayanus CBS $380^{\mathrm{T}}$ and $S$. bayanus CBS 395, as the $S$. pastorianus-type MET2 allele can be found in some $S$. bayanus strains and in the hybrid lager strains; the allele found in S. bayanus CBS 1505 and CBS 425 and in S. pastorianus may have been replaced recently in some $S$. bayanus strains, including CBS $380^{\mathrm{T}}$, by the allele found in CBS 395 ( $S$. uvarum). This correlates with the presence of two types of rDNA unit in S. bayanus CBS $380^{\mathrm{T}}$, proposed by Nguyen \& Gaillardin (1997), one related to that of $S$. pastorianus, the other to that of CBS 395 (S. uvarum).

\section{Distribution of S. cerevisiae and S. pastorianus alleles in brewing yeast strains}

Several articles from the Carlsberg laboratory (Holmberg, 1982; Pedersen, 1983, 1985, 1986; NilssonTillgren et al., 1986) have described the analysis of the restriction patterns of markers in brewing yeasts of various origins. The distribution of HIS4, LEU2 and rDNA markers seems to point towards very little variability within the group of bottom-fermenting strains. We therefore used a combination of PCR and PCR/RFLP to test the distribution of alleles of HIS4, $Y C L 008 c, M E T 2, U R A 3, M E T 10$ and rDNA NTS2 in various yeasts isolated from beer. Fourteen strains originating from the Czech Republic, most of them being used in lager beer production, four lager yeast strains originating from Munich (Germany) obtained from the Mycothèque de l'Université Catholique de Louvains, Belgium (MUCL), and two S. pastorianus strains were tested.

The results of identification of different alleles are shown in Table 5 . All of the 14 Czech strains contained both alleles of each marker tested as $S$. pastorianus with the exception of the rDNA marker (data not shown). These strains carry the $S$. cerevisiae-type allele of NTS2, as most of the strains originating from Germany (Pedersen, 1983, 1986) and the 14 brewing yeast strains from the Czech Republic cannot be distinguished in this way. This may be because they all have the same origin. On the other hand, the four MUCL strains and S. pastorianus CBS 1513 and CBS 1503 could be differentiated with all the markers tested. MUCL 28282 and MUCL 28283, isolated in German breweries, carry the $S$. pastorianus-type NTS2 sequence. This analysis, using the HIS4, YCLO08c, MET10 and URA3 genes, therefore reveals an unexpected allele distribution within yeasts of the same origin. In addition, by analysing the RFLP patterns of rDNA NTS2 and the 26S rDNA sequence, we were able to classify these strains into two groups corresponding to $S$. cerevisiae-type units and $S$. pastorianus-type units (Table 5). Some methods rely only on rDNA polymorphism to differentiate brewing and non-brewing yeast strains (Yamagishi et al., 1999). We consider, however, as exemplified here, that differentiation of hybrid strains based on rDNA polymorphism can be misleading when used alone.

\section{Distribution of the $S$. cerevisiae subtelomeric sequences in brewing yeasts}

In order to characterize the brewing yeast genome further, we applied rapid typing methods. The most useful typing methods devised for $S$. cerevisiae rely on chromosome length polymorphism assessed by electro- 


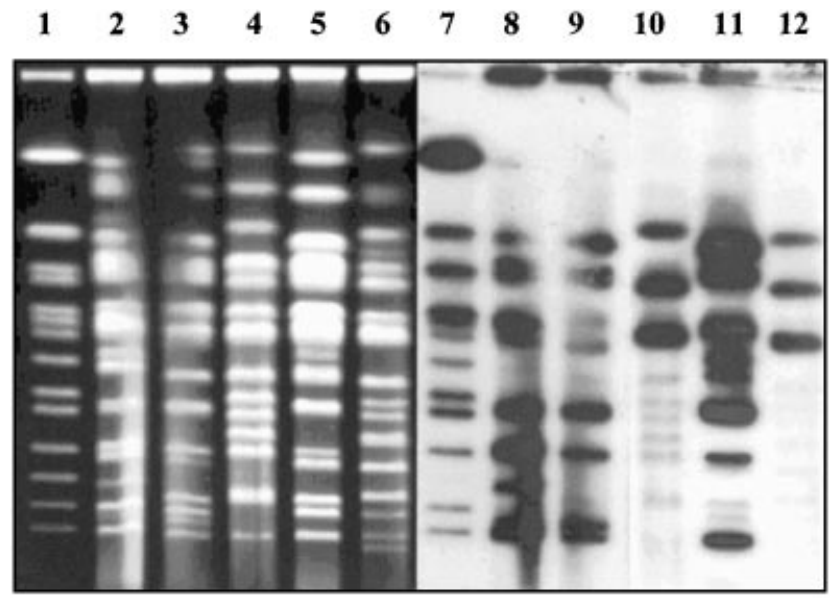

Fig. 2. Hybridization of the $S$. cerevisiae subtelomeric $Y^{\prime}$ sequence to electrophoretic karyotypes of various strains of Saccharomyces species. Lanes: 1-6, electrophoretic karyotypes; 7-12, hybridization of the $S$. cerevisiae subtelomeric $Y^{\prime}$ sequence. DNA from the following strains was used: $S$. cerevisiae YNN295 (lanes 1 and 7), S. pastorianus CBS 1513 (2 and 8), S. monacensis CBS 1503 (3 and 9), S. pastorianus NRRL $\mathrm{Y}-1551^{\top}$ (4 and 10), S. pastorianus CBS $1538^{\top}$ (5 and 11) and S. bayanus CBS 425 (6 and 12).

phoretic karyotypes and RFLP of mitochondrial (mt)DNA (Vézinhet et al., 1990). Brewing yeast electrophoretic karyotypes can be quite complex and difficult to analyse (Fig. 2). Aigle et al. (1984) have shown that mtDNA of brewing yeast is poorly polymorphic and we confirmed this observation for the 14 Czech brewing strains: we detected only one polymorphic EcoRV fragment in the mtDNA of three Czech strains (CLIB 262, CLIB 263, CLIB 264) and MUCL 28282 and MUCL 28283 (data not shown).

Because of their repetitive nature, telomeric and subtelomeric sequences have been very useful for typing wine strains of $S$. cerevisiae by hybridization (Lavallée et al., 1994). S. cerevisiae contains two types of repeated subtelomeric sequences: $Y^{\prime}$ sequences show sequence similarity to helicases and are present on most chromosome ends and $\mathrm{X}$ sequences of unknown function are present at the extremities of all chromosomes.

We used these repeated sequences to assess the presence of chromosomes or extremities of chromosomes originating from $S$. cerevisiae. The $\mathrm{Y}^{\prime}$ sequence was hybridized to electrophoretic karyotypes of brewing yeast and various $S$. bayanus isolates. The patterns could be clearly separated in two groups: simple patterns with three bands and complex patterns with more than eight bands. The strains displaying a simple pattern, with three bands of 1200,1000 and $750 \mathrm{~kb}$, exemplified by CBS 425 (Fig. 2, lanes 6 and 12), all belonged to S. bayanus (Nguyen et al., 2000). The same bands also hybridize to the $\mathrm{X}$ sequence, as a fourth band of about $600 \mathrm{~kb}$ was revealed by the $\mathrm{X}$ sequence probe on an electrophoretic karyotype of $S$. bayanus

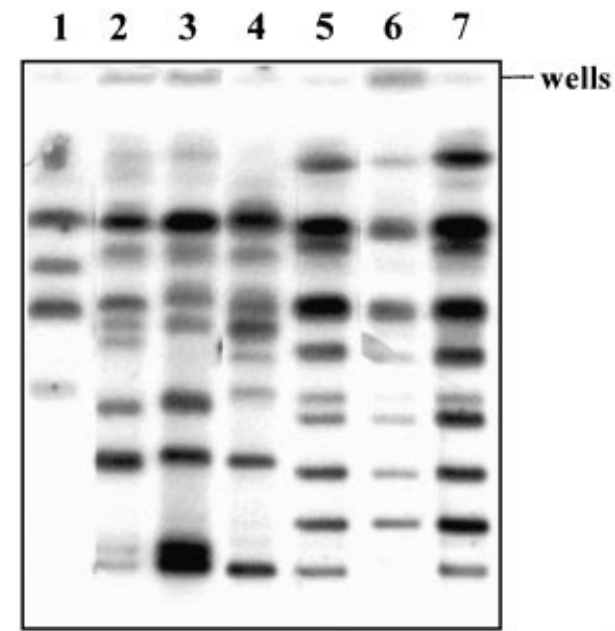

Fig. 3. Hybridization of the $S$. cerevisiae subtelomeric $X$ sequence to electrophoretic karyotypes of various brewing strains. Lanes: $1, S$. bayanus CBS $380^{\top} ; 2$, S. pastorianus CBS 1513 (S. carlsbergensis); 3, S. pastorianus CBS 1503 (S. monacensis); 4, MUCL 28282; 5, MUCL 28284; 6, CLIB 220; 7, CLIB 221.

(Fig. 3). The detection of a larger number of chromosomal bands with the $\mathrm{X}$ sequence than with the $\mathrm{Y}^{\prime}$ sequence was expected, since this type of sequence is present in all $S$. cerevisiae chromosomes, whereas $\mathrm{Y}^{\prime}$ is not (Pryde \& Louis, 1997).

$S$. cerevisiae and bottom-fermenting yeasts display the second hybridization pattern. As shown in Fig. 2, ten strong bands and two faint bands were detected in $S$. cerevisiae YNN 295 using the $\mathrm{Y}^{\prime}$ sequence as a probe (lanes 1 and 7). S. pastorianus CBS 1513 (lanes 2 and 8) and CBS 1503 (lanes 3 and 9) were in this group of strains. The same results were obtained for the MUCL strains and the Czech strains (data not shown, but see Fig. 3). CBS 1503 displayed as many hybridizing bands as did CBS 1513. This is consistent with $S$. pastorianus CBS 1503 (S. monacensis) being a hybrid. It is assumed that rearrangements occur in hybrid genomes, and work in the Carlsberg laboratory has demonstrated that sequences from both contributors have been rearranged, deleted or duplicated (KiellandBrandt et al., 1995). S. pastorianus CBS 1503 (S. monacensis) has apparently lost ScMET2, ScMET10 and $S c U R A 3$. As $\mathrm{X}$ and $\mathrm{Y}^{\prime}$ sequences are present on all of the $S$. cerevisiae chromosome ends, the number of bands detected should reflect the number of chromosomes originating from that yeast in the hybrids. Possibly, subtelomeric sequences from $S$. cerevisiae have been retained preferentially in the hybrids, in contrast to other sequences, or reamplified subsequently on non-S. cerevisiae chromosomes through telomere-telomere recombination associated with gene conversion (Wang \& Zakian, 1990; Teng \& Zakian, 1999).

Our results therefore rule out the hypothesis that the $S$. 


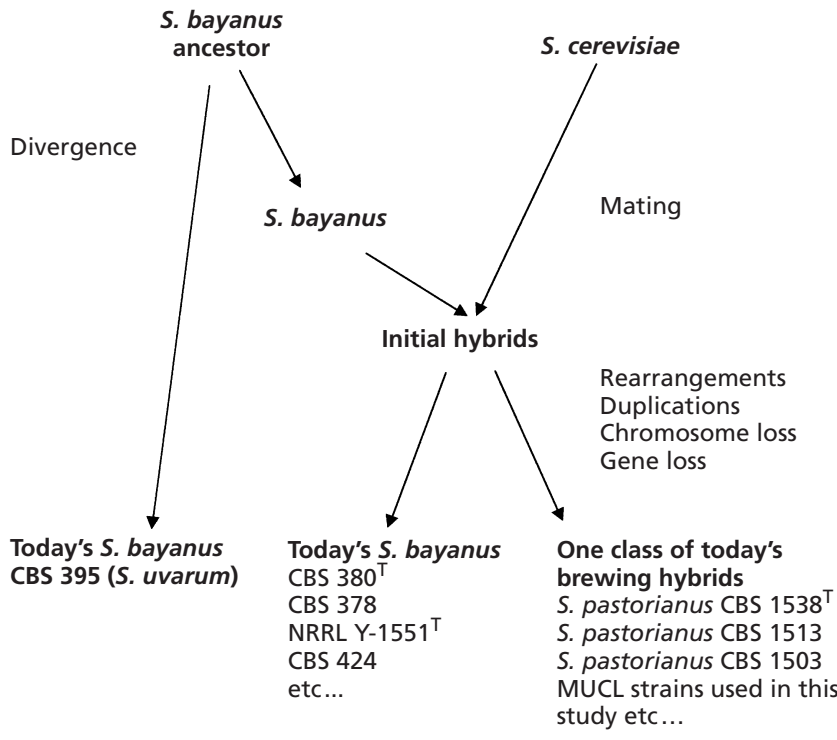

Fig. 4. Schematic representation of the formation of hybrids isolated from beer.

pastorianus hybrids arose from a single, rare mating between $S$. cerevisiae and $S$. monacensis (Pedersen, 1986; Hansen \& Kielland-Brandt, 1994). Our analysis of the origin of several genes in brewing yeasts shows clearly that many strains isolated from beer are complex hybrids, like $S$. pastorianus strains. The complete identity of several DNA sequences from the $S$. pastorianus and $S$. bayanus strains tested, including HIS4, YCLO08c, URA3 and MET10, substantiates the idea that a large number of $S$. bayanus strains on the one hand and bottom-fermenting yeasts on the other have a common ancestor.

Recently, natural isolates, involved in wine making and cider making, were found to carry hybrid genomes containing $S$. cerevisiae and $S$. bayanus material (Masneuf et al., 1998; Groth et al., 1999), indicating that the formation of hybrids in the fermentation industry is not restricted to beer making. The use of the MET2 gene sequence did not indicate to which subgroup within the $S$. bayanus species one of the non$S$. cerevisiae parents belonged. It was shown recently that $S$. bayanus CBS $380^{\mathrm{T}}$ and CBS 378 carry a sequence identical to that of $S$. cerevisiae $\mathrm{Y}^{\prime}$ (Nguyen et al., 2000). A large number of $S$. bayanus strains and all of the $S$. pastorianus strains tested here hybridized to $\mathrm{Y}^{\prime}$ sequences and could be considered hybrids, although no $S$. cerevisiae sequences other than $\mathrm{Y}^{\prime}$ were detected in the $S$. bayanus strains. Strains like CBS 1505 (S. intermedius) that do not hybridize to the $\mathrm{Y}^{\prime}$ sequence were shown to display a mixed rDNA RFLP profile (Nguyen et al., 2000). This, together with our results, suggests that a large number of hybrids might result from exchanges between $S$. cerevisiae and an ancestor common to the group of $S$. bayanus strains, followed by subsequent rearrangements and redistribution of both divergent genomes (Fig. 4).

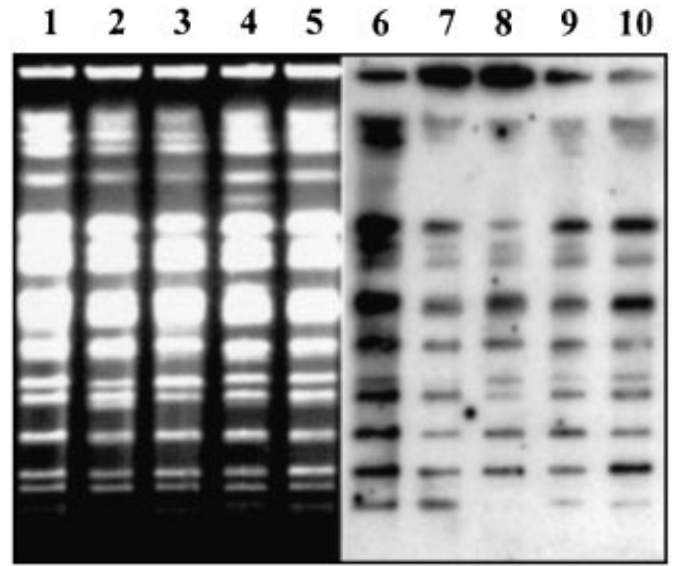

Fig. 5. Hybridization of the $S$. cerevisiae subtelomeric $X$ sequence to electrophoretic karyotypes of various Czech brewing strains. Lanes: 1-5, electrophoretic karyotypes; 6-10, hybridization of the $S$. cerevisiae $X$ sequence. DNA from the following strains was used: CLIB 261 (lanes 1 and 6), CLIB 224 (2 and 7), CLIB 225 (3 and 8), CLIB 260 (4 and 9) and CLIB 261 (5 and 10).

Surprisingly, the isolate $S$. pastorianus NRRL Y$1551^{\mathrm{T}}$, obtained from the ARS collection, possessed a simple three-band $\mathrm{Y}^{\prime}$ pattern (Fig. 2, lanes 4 and 10) and an electrophoretic karyotype similar to that of CBS $380^{\mathrm{T}}$. This was unexpected, because this strain was chosen as the representative of the hybrid species when various brewing yeasts were gathered under the generic name $S$. pastorianus (Vaughan-Martini \& Martini, 1987). We tested a second specimen of this strain, conserved at the CBS as CBS $1538^{\mathrm{T}}$. It displayed the complex $\mathrm{Y}^{\prime}$ hybridization pattern expected for a brewing yeast (Fig. 2, lanes 5 and 12). This result shows that the two specimens of the type strain of $S$. pastorianus, NRRL $\mathrm{Y}-1551^{\mathrm{T}}$ and CBS $1538^{\mathrm{T}}$, are different (compare lanes 10 and 11), consistent with the different proteomic patterns obtained by Joubert et al. (2000) for the two strains. The $Y^{\prime}$ pattern of NRRL Y$1551^{\mathrm{T}}$ is undistinguishable from that of $S$. bayanus (compare lanes 10 and 12). NRRL Y $-1551^{\mathrm{T}}$ carries the S. bayanus-type MET2 allele whereas CBS $1538^{\mathrm{T}}$ has a typical $S$. pastorianus MET2 pattern, showing the presence of both $S$. cerevisiae and $S$. pastorianus alleles. Previous results published for these two strains should clearly be reassessed in light of these findings.

Hybridization with the $S$. cerevisiae $\mathrm{X}$ sequence probe can differentiate lager strains of various origins (Fig. 3 ). We attempted to differentiate the strains originating from the Czech Republic, which appeared indistinguishable according to specific allele distribution. We observed few differences between the electrophoretic karyotypes of these strains (Fig. 5 lanes 1-5; compare lanes 2 and 3, for instance). The differences were clearly greater between the hybridization patterns obtained with the $S$. cerevisiae X sequence (Fig. 5, lanes 6-10). In addition, the relative intensity of the 
signal for bands of the same size varied according to the strain. Among the 14 strains tested, we could define five groups on the basis of the presence or absence of a signal and its relative intensity. Note that karyotypic variations and hybridization variations were not correlated.

\section{ACKNOWLEDGEMENTS}

We gratefully acknowledge Annie Auger and Andrée Lépingle for sequencing. We are very grateful to Professor Morten Kielland-Brandt for the gift of unpublished sequences and helpful discussion and to Dr E. Louis for the gift of the plasmid carrying the $\mathrm{X}$ telomeric sequence. This work was supported by the Direction des Relations Internationales of INRA.

\section{REFERENCES}

Aigle, M., Erbs, D. \& Moll, M. (1984). Some molecular structures in the genome of lager brewing yeasts. J Am Soc Brew Chem $\mathbf{4 2}$, $1-7$.

Andersen, T. H., Hoffmann, L., Grifone, R., Nilsson-Tillgren, T. \& Kielland-Brandt, M. C. (1999). Brewing yeast genetics. In Yeast Physiology. A New Era of Opportunity, EBC Monograph 28, pp. 140-147. Nürnberg: Fachverlag Hans Carl.

Barnett, J. A., Payne, R. W. \& Yarrow, D. (1990). Yeasts: Characteristics and Identification, 2nd edn. Cambridge: Cambridge University Press.

Borsting, C., Hummel, R., Schultz, E. R., Rose, T. M., Pedersen, M. B., Knudsen, J. \& Kristiansen, K. (1997). Saccharomyces carlsbergensis contains two functional genes encoding the acylCoA binding protein, one similar to the ACB1 gene from $S$. cerevisiae and one identical to the ACB1 gene from $S$. monacensis. Yeast 13, 1409-1421.

Casey, G. P. (1986a). Cloning and analysis of two alleles of the ILV3 gene from Saccharomyces carlsbergensis. Carlsberg Res Commun 51, 327-341.

Casey, G. P. (1986b). Molecular and genetic analysis of chromosomes X in Saccharomyces carlsbergensis. Carlsberg Res Commun 51, 343-362.

Church, G. M. \& Gilbert, W. (1984). Genomic sequencing. Proc Natl Acad Sci US A 81, 1991-1995.

Dear, S. \& Staden, R. (1991). A sequence assembly and editing program for efficient management of large projects. Nucleic Acids Res 19, 3907-3911.

Fujii, T., Yoshimoto, H., Nagasawa, N., Bogaki, T., Tamai, Y. \& Hamachi, M. (1996). Nucleotide sequences of alcohol acetyltransferase genes from lager brewing yeast, Saccharomyces carlsbergensis. Yeast 12, 593-598.

Gjermansen, C. (1991). Comparison of genes of Saccharomyces cerevisiae and Saccharomyces carlsbergensis. $\mathrm{PhD}$ thesis. University of Copenhagen, Denmark.

Groth, C., Hansen, J. \& Piškur, J. (1999). A natural chimeric yeast containing genetic material from three species. Int $J$ Syst Bacteriol 49, 1933-1938.

Hansen, J. \& Kielland-Brandt, M. C. (1994). Saccharomyces carlsbergensis contains two functional MET2 alleles similar to homologues from $S$. cerevisiae and S. monacensis. Gene 140, 33-40.

Hansen, J., Cherest, H. \& Kielland-Brandt, M. C. (1994). Two divergent MET10 genes, one from Saccharomyces cerevisiae and one from Saccharomyces carlsbergensis, encode the alpha subunit of sulfite reductase and specify potential binding sites for FAD and NADPH. $J$ Bacteriol 176, 6050-6058.

Hoffman, C. S. \& Winston, F. (1987). A ten-minute DNA preparation from yeast efficiently releases autonomous plasmids for transformation of Escherichia coli. Gene 57, 267-272.

Holmberg, S. (1982). Genetic differences between Saccharomyces carlsbergensis and $S$. cerevisiae. II. Restriction endonuclease analysis of genes in chromosome III. Carlsberg Res Commun 47, 233-244.

Joubert, R., Brignon, P., Lehmann, C., Monribot, C., Gendre, F. \& Boucherie, H. (2000). Two-dimensional gel analysis of the proteome of lager brewing yeasts. Yeast 16, 511-522.

Kielland-Brandt, M. C., Nilsson-Tillgren, T., Gjermansen, C., Holmberg, S. \& Pedersen, M. B. (1995). Genetics of brewing yeasts. In The Yeasts, vol. 6, 2nd edn, pp. 223-254. Edited by A. H. Rose, E. Wheals \& J. S. Harrison. London: Academic Press.

Kurtzman, C. P. \& Robnett, C. J. (1998). Identification and phylogeny of ascomycetous yeasts from analysis of nuclear large subunit (26S) ribosomal DNA partial sequences. Antonie Leeuwenhoek 73, 331-371.

Lavallée, F., Salvas, Y., Lamy, S., Thomas, D. Y., Degré, R. \& Dulau, L. (1994). PCR and DNA fingerprinting used as quality control in the production of wine yeast strains. Am J Enol Vitic 45, 86-91.

Lodder, J. \& Kreger-van Rij, N. J. W. (1952). The Yeasts, a Taxonomic Study. Amsterdam: North-Holland.

Maftahi, M., Nicaud, J.-M., Levesque, H. \& Gaillardin, C. (1995). Sequencing analysis of a $15.4 \mathrm{~kb}$ fragment of yeast chromosome XIV identifies the RPD3, PAS 8 and KRE1 loci and five new open reading frames. Yeast 11, 567-572.

Masneuf, I., Hansen, J., Groth, C., Piskur, J. \& Dubourdieu, D. (1998). New hybrids between Saccharomyces sensu stricto yeast species found among wine and cider production strains. Appl Environ Microbiol 64, 3887-3892.

Meaden, P. (1990). DNA fingerprinting of brewers' yeast: current perspectives. J Inst Brew 96, 195-200.

Naumov, G. I. (1996). Genetic identification of biological species in the Saccharomyces sensu stricto complex. J Ind Microbiol Biotechnol 17, 295-302.

Naumov, G. I., James, S. A., Naumova, E. S., Louis, E. J. \& Roberts, I. N. (2000). Three new species in the Saccharomyces sensu stricto complex: Saccharomyces cariocanus, Saccharomyces kudriavzevii and Saccharomyces mikatae. Int J Syst Evol Microbiol 50, 1931-1942.

Nguyen, H.-V. \& Gaillardin, C. (1997). Two subgroups within the Saccharomyces bayanus species evidenced by PCR amplification and restriction polymorphism of the non-transcribed spacer 2 in the ribosomal DNA unit. Syst Appl Microbiol 20, 286-294.

Nguyen, H. V., Lépingle, A. \& Gaillardin, C. A. (2000). Molecular typing demonstrates homogeneity of Saccharomyces uvarum strains and reveals the existence of hybrids between $S$. uvarum and $S$. cerevisiae, including the S. bayanus type strain CBS 380. Syst Appl Microbiol 23, 71-85.

Nilsson-Tillgren, T., Gjermansen, C., Kielland-Brandt, M. C., Petersen, J. G. L. \& Holmberg, S. (1981). Genetic differences between Saccharomyces carlsbergensis and S. cerevisiae. Analysis of chromosome III by single chromosome transfer. Carlsberg Res Commun 46, 65-76. 
Nilsson-Tillgren, T., Gjermansen, C., Holmberg, S., Petersen, J. G. L. \& Kielland-Brandt, M. C. (1986). Analysis of chromosome $\mathrm{V}$ and the ILV1 gene from Saccharomyces carlsbergensis. Carlsberg Res Commun 51, 309-326.

O'Donnell, K. (1993). Fusarium and its near relatives. In The Fungal Holomorph: Mitotic, Meiotic and Pleomorphic Speciation in Fungal Systematics, pp. 225-233. Edited by D. R. Reynolds \& J. W. Taylor. Wallingford, UK: CAB International.

Pearson, W. R. \& Lipman, D. J. (1988). Improved tools for biological sequence comparison. Proc Natl Acad Sci US A 85, 2444-2448.

Pedersen, M. B. (1983). DNA sequence polymorphisms in the genus Saccharomyces. I. Comparison of the HIS4 and ribosomal RNA genes in lager strains, ale strains and various species. Carlsberg Res Commun 48, 485-503.

Pedersen, M. B. (1985). DNA sequence polymorphisms in the genus Saccharomyces. II. Analysis of the genes RDN1, HIS4, $L E U 2$, and $T y$ transposable elements in Carlsberg, Tuborg and 22 Bavarian brewing strains. Carlsberg Res Commun 50, 263-272.

Pedersen, M. B. (1986). DNA sequence polymorphisms in the genus Saccharomyces. III. Restriction endonuclease fragment patterns of chromosomal regions in brewing and other yeast strains. Carlsberg Res Commun 51, 163-183.

Porter, G., Westmoreland, J., Priebe, S. \& Resnick, M. A. (1996). Homologous and homeologous intermolecular gene conversion are not differentially affected by mutations in the DNA damage or the mismatch repair genes $R A D 1, R A D 50, R A D 51, R A D 52$, RAD54, PMS1 and MSH2. Genetics 143, 755-767.

Pryde, F. E. \& Louis, E. J. (1997). Saccharomyces cerevisiae telomeres. A review. Biochemistry 62, 1232-1241.

Sambrook, J., Fritsch, F. E. \& Maniatis, T. (1989). Molecular Cloning : a Laboratory Manual, 2nd edn. Cold Spring Harbor, NY : Cold Spring Harbor Laboratory.

Sherman, F., Fink, G. R. \& Hicks, J. B. (1986). Methods in Yeast
Genetics. Cold Spring Harbor, NY: Cold Spring Harbor Laboratory.

Tamai, Y., Momma, T., Yoshimoto, H. \& Kaneko, Y. (1998). Coexistence of two types of chromosome in the bottom fermenting yeast, Saccharomyces pastorianus. Yeast 14, 923-933.

Teng, S. C. \& Zakian, V. A. (1999). Telomere-telomere recombination is an efficient bypass pathway for telomere maintenance in Saccharomyces cerevisiae. Mol Cell Biol 19, 8083-8093.

Vaughan-Martini, A. \& Kurtzman, C. P. (1985). Deoxyribonucleic acid relatedness among species of Saccharomyces sensu stricto. Int J Syst Bacteriol 35, 508-511.

Vaughan-Martini, A. \& Martini, A. (1987). Three newly delimited species of Saccharomyces sensu stricto. Antonie Leeuwenhoek 53, 77-84.

Vaughan-Martini, A. \& Martini, A. (1998). Saccharomyces Meyen ex Reess. In The Yeasts, 4th edn, pp. 358-373. Edited by C. P. Kurtzman \& J. W. Fell. Amsterdam: Elsevier.

Vézinhet, F., Blondin, B. \& Hallet, J.-N. (1990). Chromosomal DNA patterns and mitochondrial DNA polymorphism as tools for identification of enological strains of Saccharomyces cerevisiae. Appl Microbiol Biotechnol 32, 568-571.

Wang, S. S. \& Zakian, v. A. (1990). Telomere-telomere recombination provides an express pathway for telomere acquisition. Nature 345, 456-458.

Yamagishi, H. \& Ogata, T. (1999). Chromosomal structures of bottom fermenting yeasts. Syst Appl Microbiol 22, 341-353.

Yamagashi, H., Otsuta, Y., Funahashi, W., Ogata, T. \& Sakai, K. (1999). Differentiation between brewing and non-brewing yeasts using a combination of PCR and RFLP. J Appl Microbiol 86, 505-513.

Zimmermann, M. \& Fournier, P. (1996). Electrophoretic karyotyping of yeast. In Genetics, Biochemistry and Molecular Biology of Non-conventional Yeasts-a Laboratory Manual. pp. 101-116. Edited by K. Wolf. Heidelberg: Springer. 